\title{
Toxoplasma gondii infection and neuropsychiatric disease: current insight
}

This article was published in the following Dove Press journal:

Reports in Parasitology

22 September 2015

Number of times this article has been viewed

\section{Dunja Hinze-Selch}

Fachkliniken St. Marien - St Vitus $\mathrm{GmbH}$, Fachklinik St Marienstift Dammer Berge, NeuenkirchenVörden, Germany
Correspondence: Dunja Hinze-Selch Fachkliniken St Marien - St Vitus GmbH, Fachklinik St Marienstift Dammer Berge, Dammer Strasse 4a, D-49434 Neuenkirchen-Vörden, Germany Tel +495493502I50

$\mathrm{Fax}+495493502189$

Email dunja.hinze-selch@suchtfachkliniken.de

\begin{abstract}
Toxoplasma gondii has always been associated with severe medical disease when acquired congenitally or under immunocompromised conditions. However, in the last decade, intensive research has shed light on Toxoplasma gondii as a latent chronic infection producing distinct neuropsychiatric symptoms and alterations in its intermediate hosts, such as humans and rodents. The peculiarities described range from the well-established attenuated odor aversion paradigm toward cat urine, in infected rodents to significant associations with psychiatric disorders such as schizophrenia or bipolar disorder, to cognitive impairments, and increased traffic accidents. In relation to what has already been investigated to date, how could we explain such effects on the basis of what we know about the complex interplay of this intracellular permanent parasite and its host? This review systematically screens the recent literature, presents results from a physician's point of view, and discusses possible mechanisms and further research lines.
\end{abstract}

Keywords: Toxoplasma gondii, neuropsychiatric, psychiatric, behavior

\section{Introduction}

There is growing data published, and evidence to show that Toxoplasma gondii (TG) infection is associated with distinct neuropsychiatric peculiarities even in immunocompetent hosts. Certain diagnoses were associated with TG infection in humans, ranging from neurologic diseases such as Parkinson's disease, ${ }^{1}$ to pure psychiatric disorders such as schizophrenia and affective disorders. ${ }^{2-4}$ On the other hand, behavioral peculiarities and changes have been described in animals and humans associated with TG infection. The attenuated normal aversion, fear, and flight of infected rats from cat urine odor has been shown in several studies and appears to be a teleologic helpful behavior change in the mice in order to help the TG parasite to expand. ${ }^{5}$ Other behavioral changes particularly in humans do not appear that understandable. However, fact seems to be that TG infection does have a significant impact on human and animal behavior. ${ }^{6}$

The growing body of literature on TG and particularly psychiatric disorders and syndromes in the past 5-10 years is most likely through a funding issue. While in the 1990s, the idea of behavioral changes caused by a chronic infection such as TG was broadly judged as naïve, the strong belief of Fuller Torrey that there is an impact ${ }^{7-10}$ led to impressive funding in this line in the 2000s. Thus, on the one hand, data emerged that supported Fuller Torrey's belief, and on the other hand in addition, the publication bias disappeared. Therefore, our knowledge has been sufficiently grown over the past 10 years. 
It is now known that TG infection is associated with several neuropsychiatric diseases and behavioral changes in humans and animals, though it is not yet understood how it happens and what the mechanisms are. However, there is growing data showing that the mechanisms are complex, comprising humoral, immune, neurotransmitter, epigenetic, genetic, and structural effects. ${ }^{11}$

This review will present results of an up-to-date literature search in the well-established, biomedically oriented, and sound PubMed database; put together all diverse perspectives; and provide conclusions as well as speculations on the basis of the presented literature from a physician's point of view.

\section{Materials and methods}

A literature search was done making use of the well-established, scientifically sound, and biomedically oriented government-run PubMed database on the following search terms: for TG and neuropsychiatric peculiarities, "Toxoplasma* and neuropsych*" was used; for TG and psychiatric peculiarities, "Toxoplasma* and psych*" was used; for TG and schizophrenia, "Toxoplasma* and schizophr*" was used; for TG and behavior, "Toxoplasma* and behavior" was used; and for TG and neurologic peculiarities, "Toxoplasma* and neurol*" was used. The results then were counted by the year of publication before 2000, 2000 through 2009, 2010, and later, by the category of review vs other types of articles.

The body of this literature search is the basis of this article.

\section{Results}

\section{Publications by number and year}

As can be seen from Table 1, the largest body of literature is with the search categories TG and neurologic peculiarities with 509 papers; the percentage of review papers is $14 \%$. The second largest body of literature is with the search categories TG and behavior with 350 publications and without any effects of the years of publication, review article comprise approximately $11 \%$ of these 350 papers. The papers on human behavior seem to slow down with time, whereas the ones on animal behavior have been growing over time. The third largest body of literature is with the search categories TG and schizophrenia with 158 papers, and here the number of publications does impressively increase over time; $18 \%$ are reviews. The number of publications with the search categories TG and psychiatric peculiarities is still quite large with 146 papers showing the same impressive increase of publications over the years; only $12 \%$ are reviews. The very smallest number of publications is with the search categories TG and neuropsychiatric peculiarities with 37 papers only, also increasing dominantly over time; $16 \%$ reviews.

These numbers demonstrate that there are numerous publications and international and peer-reviewed data on the issue of TG and its impact on brain functions. Research on psychiatric outcomes has impressively increased during the last 5 years, whereas research on neurologic outcomes seems to have decreased. With this respect, it is noteworthy that one funding source, The Stanley Medical Research Institute (SMRI), has started to push research on possible associations between TG infection and the diagnosis of schizophrenia in the late 1990. The idea was that schizophrenia has increased in Western societies with the growing cat-holdership indoors, and many individuals with schizophrenia had cats during their life span. ${ }^{10,12}$ This hypothesis did not find significant followers until Fuller Torrey got funding for research by the SMRI in the 1990s. If checked for the funding source, many of the publications from 2000 till today were funded by the SMRI. This enormous flood of data has shed light on TG and its effects on brain functions and behavior within only approximately 15 years, while TG infection has been known for more than 100 years already in humans.

Thus, we ask, what kinds of publications are there, and what do they tell us?

Table I Results of the PubMed search by number and years

\begin{tabular}{|c|c|c|c|c|c|}
\hline & Total number & Before 2000 & 2000-2009 & $2010-2015$ & Review articles \\
\hline TG + neuropsychiatric peculiarities & 37 & 3 & 7 & 27 & $6(16 \%)$ \\
\hline TG + psychiatric peculiarities & 146 & 21 & 37 & 88 & $18(12 \%)$ \\
\hline TG + schizophrenia & 158 & 5 & 58 & 95 & $29(18 \%)$ \\
\hline TG + behavior & 350 & 115 & 101 & 134 & $39(11 \%)$ \\
\hline TG + behavior, humans only & 207 & 86 & 63 & 58 & $33(16 \%)$ \\
\hline TG + neurologic peculiarities & 509 & 244 & 133 & 132 & $72(14 \%)$ \\
\hline
\end{tabular}

Notes: Listed are the search categories used with the total number of publications and the subsequent partition numbers by year of publication. The Review articles column give the total number of reviews among the total number of papers, and the percentage refers to this.

Abbreviation: TG, Toxoplasma gondii. 


\section{Publications by species}

As mentioned earlier, there are data on TG infection in humans and in animals.

\section{Publications on animals}

In a recent publication, Parlog et a ${ }^{13}$ present a murine model of chronic toxoplasmosis. They demonstrate that TG infection alters synaptic connectivity in distinct brain regions by modulating two key synaptic proteins, PSD95 and synaptophysin. In particular, the somatosensory cortex and the hippocampus were affected by a higher density of the TG lesions and activated residential glial cells as well as recruited immune cells. Quite in this line are the data by Evans et $\mathrm{al}^{5}$ in rats. They showed that the localization of the TG cysts in the forebrain hand in hand with the immune reaction to the cysts is related to altered rat behavior, in particular the attenuation of predator odor aversion and anxiety. These latter behavioral changes in rats and mice have stimulated teleologic thoughts: TG might manipulate the behavior of its intermediate host so that the host becomes maximally prone to help propagate TG infection. If infected rats and mice moved deliberately toward the cats' mouth, it could easily be conceived that TG would expand throughout all intermediate and final hosts across species. However, still it is puzzling how TG can manage this. Gatkowska et a ${ }^{14}$ showed that TG infection in mice differentially modulated the monamine neurotransmitters in various brain regions with distinct differences between sexes. In this line is the finding that dopamine, one of the monamine neurotransmitters, by itself facilitates propagation of the TG cysts. ${ }^{15}$ Thus TG, a parasite at its best, makes use of its host's organism in order to propagate its own life.

\section{Publications on humans}

There is a large body of literature associating particularly psychiatric but also some neurologic diseases, disorders, and diagnoses with TG infection by data on seroprevalence and/ or serointensity of anti-TG antibody responses.

\section{TG and neurologic diseases}

With respect to neurologic diseases, there are data on Alzheimer's dementia, Parkinson's disease, epilepsy, and multiple sclerosis. Kusbeci et a $1^{16}$ showed that seroprevalence, ie, anti-TG antibody titer, exceeds the cut-off, and serointensity, ie, the extension of the anti-TG titer above cut-off, were significantly increased with respect to IgGantibodies in patients with Alzheimer's disease compared to matched controls. Conterintuitively, Jung et al ${ }^{17}$ suggest from their mouse model on Alzheimer's disease that acute TG infection might attenuate particularly the cognitive symptoms by immunosuppressive mechanisms. On the other hand, in humans, the rate of infected individuals in a population increases with age reaching its plateau about already before the age of 60 so that acute infection in naïve individuals is rare after this age suggesting that a positive immunosuppressive effect by TG infection might not be particularly relevant by epidemiology. ${ }^{18}$ Miman et al ${ }^{1}$ report a significant increase in seroprevalence in their patients with Parkinson's disease compared to controls, whereas Celic et al ${ }^{19}$ did not find any differences in their Parkinson's patients. With respect to epilepsy, there are many publications but on epilepsy associated with toxoplasmosis exclusively, there are very few ones only. A very recent systematic literature review found six publications with sound data leading to a calculated odds ratio (OR) by a random effects model of 2.25 in favor of epileptic seizures associated with TG infection in humans. ${ }^{20}$ With respect to multiple sclerosis, there is one seroprevalence study reporting a trend of increase in the patients compared to controls. ${ }^{21}$ In summary, there are few data on associations between TG infection and primary neurologic diseases; the vast body of literature is on various neurologic symptoms and possible associations with TG infection or TG infection in immunocompromised humans. ${ }^{22-24}$

\section{TG and psychiatric disorders}

With respect to psychiatric disorders, there are many data published, most on the diagnosis of schizophrenia. Actually, the first publication ever found in PubMed by our search terms is by Delgado Garcia and Garcia Landa in 1979 using the intradermal test against toxoplasmin in schizophrenic patients vs controls. ${ }^{25}$ The first publication using blood antibody testing is by Choi et $\mathrm{al}^{26}$ from South Korea in 1983, describing a slightly higher percentage of infected individuals with schizophrenia or bipolar disorder among all psychiatric patients (1.9\%) compared to healthy controls $(1.3 \%)$. Almost 20 years later, the next publication came up describing significantly increased anti-TG IgG, IgM, and IgA titers in the first-episode schizophrenic patients. ${ }^{27}$ There have been numerous publications in various patient samples and ethnicities from almost all over the world, for the most part showing increased seroprevalence and/or serointensity in individuals with schizophrenia. ${ }^{18,26-34,2,35}$ As we discussed in our large-scale epidemiologic study, ${ }^{18}$ it is critical to choose carefully the control groups and control conditions because of the nature of TG infection, eg, with respect to age, residential region, certain eating habits, and cat ownership. The few studies not finding significant 
effects with respect to the diagnosis of schizophrenia, for the most part did not carefully select the control groups, reported seroprevalence only which is not fundamentally different between patients and controls, or relied on one antibody class only, for the most part being IgG. The complex plasma antibody response to TG infection as well as the to date knowledge on the whole complex immune control in humans - with the antibody response playing no significant role - can be reviewed in, eg, Dupont et al. ${ }^{36}$ With respect to the human seroprevalence and intensity studies, bottom line is that diverging from many other infections and standard medical truth, IgM antibodies do not mean acute infection and disappear several weeks thereafter with IgG antibodies emerging and persisting. Still it is critical to interpret serologic TG antibody data with respect to state, duration, and activity of this chronic infection acknowledging that the antibody response does not seem to be a causal, critical mechanism of defense but rather a consequence of such mechanisms; however, it is crucial for clinical diagnostic reasons. ${ }^{37}$ In this line, the more recent efforts to link TG infection in schizophrenic individuals with the course of the schizophrenic disorder or the particular symptomatology still need to be considered with caution. However, Flegr's very recent review argues already for such associations. ${ }^{38}$

With respect to affective disorders, there are data from the third National Health and Nutritional Survey from the US showing that only bipolar disorder was significantly associated with increased seroprevalence of TG infection but not all other kinds of depressive only disorders. ${ }^{39}$ This is in line with a study from France reporting an OR of 2.7 among all seropositive patients for having bipolar disorder ${ }^{40}$ and a recent study from the US in patients with mania reporting an OR of 2.3. ${ }^{41}$ In our large-scale epidemiologic study, we did not find differences in seroprevalence but increased serointensity in patients with schizophrenia, with major depression as well as by a trend with bipolar disorder. ${ }^{18}$

There are scattered data for further psychiatric diagnoses, such as anxiety disorders and personality disorders. Anxiety disorders were recently shown not to be associated with higher seroprevalence but possibly with increased serointensity, ${ }^{42}$ whereas the additional diagnosis of a personality disorder in psychiatric patients was shown to significantly increase the likelihood for TG seropositivity. ${ }^{43}$

Substances effective in the treatment of bipolar or schizophrenic disorder have been shown to also modulate reproduction of TG during in vitro cultivation. ${ }^{44,45}$ Furthermore, treatment trials have been done with add-on anti-Toxoplasma medication in seropositive psychiatric patients with schizophrenia or bipolar disorder. ${ }^{46,47}$ These data support the idea that TG might be involved in the pathophysiology.

However, looking back, all these data are critical with psychiatric diagnoses which are hypothetical clusters of symptoms which on their part are behavioral extracts (Figure 1). Thus, if the hypothesis on a psychiatric diagnosis is wrong, research data on this diagnosis will never yield concise results. Therefore, dealing with the aforementioned behavioral extracts appears much more promising.

\section{TG and behavior}

Moreover, there are data on TG infection and human behavior. Stock et $\mathrm{al}^{48}$ tested a neurophysiological stop-change behavioral paradigm in healthy young individuals and found that those with latent TG infection had faster reaction times; faster reaction times are generally viewed as preferable, although this is questionable because from such experimental paradigms, there are no references to real human every-day-life-behavior. What reaction times are relevant for normal functioning? What is the range? Thus, as with all of these kinds of data which definitely do enrich our knowledge and understanding on the complex behavior and its modulation by TG infection, the categories of better and worse as well as the extension to usefulness in real life are to be left open. Pearce et $\mathrm{al}^{49}$ found that TG-seropositive individuals had significant slowing in the acoustic startle response paradigm with the schizophrenic-seropositive individuals showing the slowest response latencies. These results are in line with a study by Priplatova et $\mathrm{al}^{50}$ but they found in addition that this slowing attenuated with increasing duration of TG infection. Zhang et $\mathrm{al}^{51}$ reported that among their 54 suicide attempters in Sweden, seropositivity and intensity to TG infection significantly increased the probability of having a history of self-directed violence (ORs of 7.12 and 2.01) compared to the seronegative suicide attempters. These data are in line with a large population-based study from Denmark, which included TG testing of more than 45,000 mothers at the time of delivery, and for the following 11-15 years. ${ }^{52}$ Women had an increased relative risk between 1.5 and 2.0 for self-directed violence, violent suicide attempts, and suicide when seropositive for TG at delivery, and the

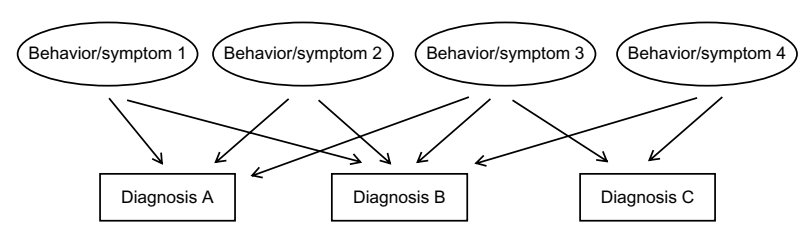

Figure I Basic structure of neuropsychiatric diagnoses by behaviors/symptoms. 
higher the titers at delivery the higher their risk. A study from Mexiko found that serointensity is significantly associated with suicide attempts in psychiatric outpatients and not with seroprevalence per se. ${ }^{53}$ However, seropositivity was significantly associated with reflex impairment in neurologic examination, with increased travel activity and snake meat consumption.

The latter issue points to the still controversial discussion on how individuals acquire TG infection and whether socioeconomic and/or behavioral consequences of neuropsychiatric disease increase the likelihood for infection. In this line, does TG infection in humans modulate behavior in such a way that these individuals are more prone to reactivate/reinfect themselves with $\mathrm{TG}$ over and over being intermediate host for this infection? Whereas in rodents, the TG-induced impairment in the predator odor aversion behavior ${ }^{54-59}$ appears clearly teleologic in order to propagate TG, behavioral modulations in humans by TG infection in order to propagate TG seem much more complex and difficult to unravel if existing at all.

Flegr reviews the whole body of literature on associations between TG infection and behavioral paradigms as well as certain behaviors or consequences from behaviors such as excessive weight gain during pregnancy and increased risk of traffic accidents. ${ }^{60,61}$ Cognitive functioning by several paradigms has been investigated and found to be impaired in TG-infected individuals without and with certain psychiatric disorders. ${ }^{62,63}$ Recent research has also pointed to relevant cognitive performance impairment in TG-infected elderly individuals leaving broad executive functioning unimpaired. ${ }^{64,65} \mathrm{~A}$ very recent large population-based investigation in humans demonstrates by regression analysis that all kinds of cognitive impairments and variations also interact with sociodemographic variables such as the income-topoverty ratio. ${ }^{66}$ These data emphasize once more that the interplay between TG and the human intermediate host is not restricted to biological mechanisms, but also affects the human host in his/her psychosocial network.

\section{TG and its in-host-mechanisms of action}

Recent approaches make use of high-throughput-technology such as genome analyses for activated genes, finding many immune and other gene activation overlapping in TG infection and various diseases. ${ }^{67}$ Another hypothesis-driven approach is on the effects of dopamine on TG. Strobl et $\mathrm{a}^{15}$ found that in vitro dopamine activated TG toward tachyzoites and their proliferation in human fibroblasts and neonatal rat astrocytes. Dopamine excess on its part plays a role in the pathophysiology of schizophrenia and psychosis, in behavioral paradigms of behavioral control as well as in the kynurenine pathway induced by intracerebral TG infection. ${ }^{6,69}$ In a very recent study, Xiao et al demonstrated that microRNA-132, a cyclic AMP-responsive element binding (CREB)-regulated microRNA was systematically upregulated by all of their three TG strains used. ${ }^{70}$ By cross-linking microRNA-132 activity with transcriptome activity of TG, dopamine signaling was the strongest associated pathway. In mice, TG infection was followed by microRNA-132 upregulation leading to imbalance in monaminergic neurotransmitter systems, which can be associated with various behavioral and neuropsychiatric disease models in humans and animals. Jia et al likewise found upregulated immune transcriptomes in their murine model after TG infection with distinct effects by two different TG strains. ${ }^{71}$ With respect to immunologic mechanisms of host response and behavioral impact, there is the hypothesis of a T-helper-1-T-helper-2 imbalance and possibly CD8-mediated effect by latent TG infection coupling with such findings in psychiatric disorders. ${ }^{72}$ Another major immune and neurotransmission player is interferon-gamma that definitely is involved in immune response against $\mathrm{TG}$ even if the leading pathways remain unclear. ${ }^{73,74}$ Thus, "how and why Toxoplasma makes us crazy" ${ }^{60}$ is still unknown and many data and hypotheses interact on many interfaces between TG infection and behavioral peculiarities.

\section{TG and its "gut feeling"}

As TG typically is ingested orally, the gut mucosal immune system plays a crucial role in the systemic dissemination of TG. Findings of increased antibody titers toward nutritional antigens in schizophrenic or bipolar patients led to investigate associations between TG immunity and nutritional antibodies in these patients as well as to thoughts on how TG invades the gut mucosal barrier. ${ }^{75,76}$ Ontogenetically in parts derived from neural crest, the gut is much more neural networks and close to the nervous system than commonly perceived so that the emerging look at and findings on mucosal and brain immunity do make sense. ${ }^{77-79}$

In line with this are findings on obesity and TG infection. Reeves et al reported an OR of 2 for obesity in psychiatrically healthy subjects with TG infection compared to those negative for TG infection. ${ }^{80}$ This could also be associated with interference of $\mathrm{TG}$ infection with the hypothalamus-pituitary-adrenal hormonal axis as well as steroid hormonal systems in general and the regulation of hunger and appetite as well as cholesterol metabolism. ${ }^{81}$ 
A
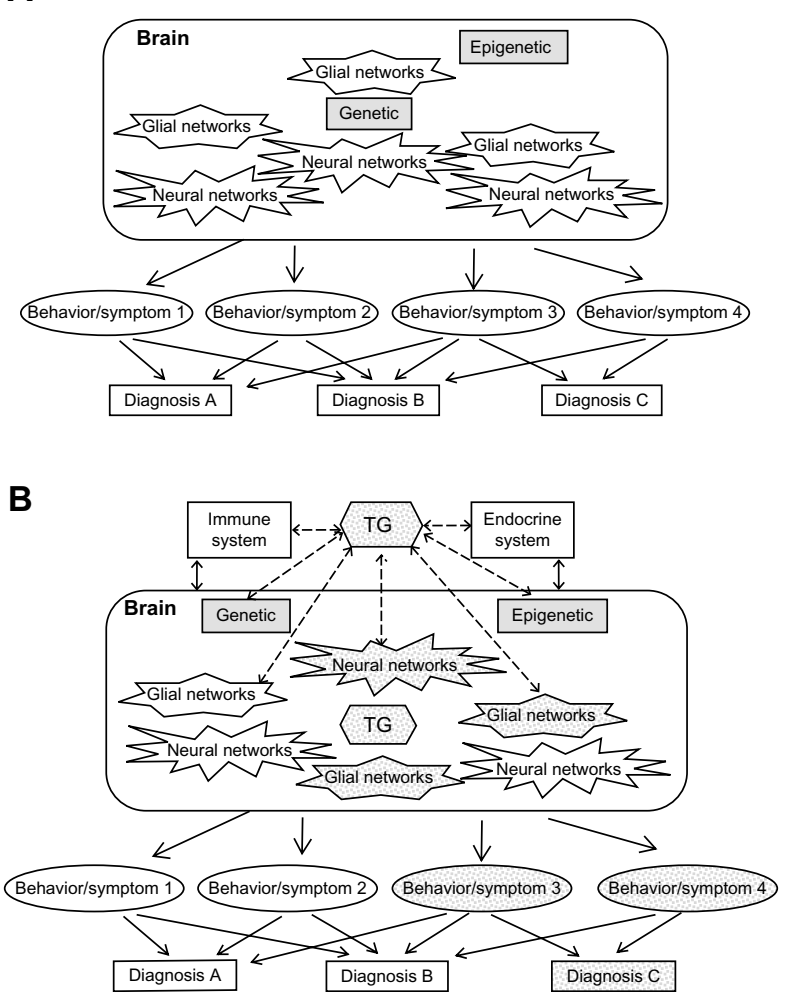

Figure 2 How the brain creates behaviors/symptoms and consequent diagnoses.

Notes: Panel (A): Basic mechanisms of the brain to create behavior. Panel (B): Impact of TG infection on the brain and its basic mechanisms to create behavior. For a further description of the diagnoses $A$ to $C$ as well the behaviors/symptoms I to 4 , please refer to Figure $I$ and the corresponding text parts of this article.

Abbreviation: TG, Toxoplasma gondii.

In this line are thoughts on increased cardiovascular risk in TG infected individuals. However, to date there are very few data only displaying a complex interaction that could induce higher cardiovascular disease as well as lower incidence depending on many more intervenient variables that still need to be unpuzzled. ${ }^{82,83}$

Another point of interest is the finding that peripheral blood mononuclear cells displayed divergent immune and inflammatory responses depending on the schizophrenic patients being obese or not. ${ }^{84}$ Studies on eating behavior, TG infection, and neuropsychiatric diseases or behavior have not yet been published. However, our study on the behavior paradigm of delay of gratification in schizophrenic individuals with reference to eating behavior demonstrated impaired behavioral control of the patients on their eating behavior; unfortunately, we did not investigate TG serologies. ${ }^{85}$

So what do we know, and what can we make from all this knowledge as displayed in this article?

\section{Discussion/conclusion}

There is sufficient evidence that TG infection modulates behavior in humans as well as in animals and is more frequent in neuropsychiatric diseases such as schizophrenia, bipolar disorder, possibly Alzheimer's dementia, epilepsy, and Parkinson's disease, and TG infection might even play a role in obsessive-compulsive and addiction disorders. ${ }^{86}$ However, there are no 1:1 relationships. Thus, TG infection does not cause schizophrenia and does not exclusively drive any behavior. On the other hand, TG infection interferes with many molecular, cellular, and organismic systems of the host. With respect to the topic of this review article on neuropsychiatric disease, we suggest the following perspectives.

As can be seen from Figure 2A, the brain represents a system of abundant plastic neural networks functioning mainly but not exclusively through neurotransmitters. To our knowledge today, we may assume that every single human brain is unique by its genetics as well as its epigenetic and environmentally induced imprints by life history. The diverse neural networks are able to induce various behaviors. A distinct cluster of behaviors can be summarized with certain neuropsychiatric diagnoses such as schizophrenia or bipolar disorder. Thus, the bases of neuropsychiatric disorders are certain behaviors. Therefore, research on these target behaviors might be more elucidating than research on the diagnoses as a whole. As can be seen in the figures of this 
article, diagnoses are arbitrary clusters of symptoms named diagnosis $\mathrm{A}, \mathrm{B}$, or $\mathrm{C}$, whereas the individual symptoms and behaviors are much closer to pathophysiology, and coincide with more than one diagnosis.

As displayed in Figure 2B, TG in particular and any other neurotropic infection likewise interact with at least the immune and endocrine systems also targeting the brain. Thus, neuronal networks will be modulated producing diverse behaviors that then might cluster for psychiatric diagnoses. TG seems to be a very potent infectious modulator because as intracellular parasite, it remains active during the whole lifespan of its host and needs to arrange with its host: a) TG remains alive, b) the host remains alive, c) the host becomes prone to help TG to propagate, ie, TG is spread through as many primary and intermediate hosts as possible. In this line, mice and rats approach cats to be eaten and infecting the cats that on their part then approach humans for infecting them and once having them infected humans keep the cats and develop behavior depending on their unique brain in interaction with the unique strain abilities of TG that is helpful in keeping TG alive. This teleologic view is supported by Torrey and Yolken ${ }^{12}$ and today in light of all the aforementioned data appear much less naïve than 20 years before. Furthermore, this significant increase in knowledge is essentially the outcome of the research funding initiatives of the SMRI in the 1990s. Thus, consequent and sufficient funding courageous enough to go for non-main-stream-research can induce significant knowledge and induce new mainstreams.

We know that successful psychotherapy, without any additional effects by substances, activates intracellular CREB-signaling pathways, with improvements in depressive behaviors. ${ }^{87} \mathrm{We}$ also know that maternal cigarette smoking during pregnancy structurally modifies the infants' brains with the consequence of distinctly impaired reward managing behavior making them prone to addictive behavior. ${ }^{88}$ We know that emotional maltreatment of infants leads to addiction behavior later in life, associated with impaired learning and reward managing behavior. ${ }^{89}$ Thus, manifest latent intracellular parasite TG should be investigated for its ability to modulate human and animal behavior.

Furthermore, specific research is needed to unravel the strategies of TG. However, any kind of research done in this line will be worth it, and will unravel many fundamental facts about human and animal behavior.

\section{Disclosure}

With respect to research in the field of Toxoplasma gondii, the author received research funding from the SMRI for a large epidemiologic study and a treatment trial, between 2001 and 2010. The author reports no other conflicts of interest in this work.

\section{References}

1. Miman O, Kusbeci OY, Aktepe OC, Cetinkaya Z. The probable relation between Toxoplasma gondii and Parkinson's disease. Neurosci Lett. 2010;475(3):129-131.

2. Torrey EF, Yolke RH. Toxoplasma gondii and schizophrenia. Emerg Infect Dis. 2003;9(11):1375-1380.

3. Hinze-Selch D. Infection, treatment and immune response in patients with bipolar disorder versus patients with major depression, schizophrenia or healthy controls. Bipolar Disord. 2002;4 Suppl 1:81-83.

4. Delgado-Garcia G, Rodriguez Perdomo E. Reactivity of toxoplasmin intradermal test in neurotic and manic-depressive patients. Rev Cubana Med Trop. 1980;32(1):35-39.

5. Evans AK, Strassmann PS, Lee IP2, Sapolsky RM. Patterns of Toxoplasma gondii cyst distribution in the forebrain associate with individual variation in predator odor avoidance and anxiety-related behavior in male Long-Evans rats. Brain Behav Immun. 2014;37:122-133.

6. Flegr J, Preiss M, Klose J, Havlícek J, Vitáková M, Kodym P. Decreased level of psychobiological factor novelty seeking and lower intelligence in men latently infected with the protozoan parasite Toxoplasma gondii Dopamine, a missing link between schizophrenia and toxoplasmosis? Biol Psychol. 2003;63(3):253-368.

7. Torrey EF. Stalking the Schizovirus. Schizophr Bull. 1988;14(2): 223-229.

8. Torrey EF, Yolken R. Could schizophrenia be a viral zoonosis transmitted from house cats? Schizophr Bull. 1995;21(2):167-171.

9. Torrey EF, Miller J, Rawlings R, Yolken RH. Seasonality of births in schizophrenia and bipolar disorder: a review of the literature. Schizophr Res. 1997;28(1):1-38.

10. Torrey EF, Yolken RH. The schizophrenia-rheumatoid arthritis connection: infectious, immune, or both? Brain Behav Immun. 2001;15(4): 401-410.

11. Camus D, Zalis MG, Vannier-Santos MA, Banic DM. The art of parasite survival. Braz J Med Biol Res. 1995;28(4):399-413.

12. Torrey EF, Yolken RH. The urban risk and migration risk factors for schizophrenia: are cats the answer? Schizophr Res. 2014; 159(2-3):299-302.

13. Parlog A, Harsan LA, Zagrebelsky M, et al. Chronic murine toxoplasmosis is defined by subtle changes in neuronal connectivity. Dis Model Mech. 2014;7(4):459-469.

14. Gatkowska J, Wieczorek M, Dziadek B, Dzitko K, Dlugonska H. Sex-dependent neurotransmitter level changes in brains of Toxoplasma gondii infected mice. Exp Parasitol. 2013;133(1):1-7.

15. Strobl JS, Goodwin DG, Rzigalinski BA, Lindsay DS. Dopamine stimulates propagation of Toxoplasma gondii tachyzoites in human fibroblast and primary neonatal rat astrocyte cell cultures. $J$ Parasitol. 2012;98(6):1296-1299.

16. Kusbeci OY, Miman O, Yaman M, Aktepe OC, Yazar S. Could Toxoplasma gondii have any role in Alzheimer disease? Alzheimer Dis Assoc Disord. 2011;25(1):1-3.

17. Jung BK, Pyo KH, Shin KY, et al. Toxoplasma gondii infection in the brain inhibits neuronal degeneration and learning and memory impairments in a murine model of Alzheimer's disease. PLoS One. 2012; 7(3):e33312.

18. Hinze-Selch D, Däubener W, Eggert L, Erdag S, Stoltenberg R, Wilms S. A controlled prospective study of Toxoplasma gondii infection in individuals with schizophrenia: beyond seroprevalence. Schizophr Bull. 2007;33(3):782-788.

19. Celik T, Kamişli O, Babür C, Cevik MO, Oztuna D, Altinayar S. Is there a relationship between Toxoplasma gondii infection and idiopathic Parkinson's disease? Scand J Infect Dis. 2010;42(8):604-608.

20. Ngoungou EB, Bhalla D, Nzoghe A, Dardé ML, Preux PM. Toxoplasmosis and epilepsy - systematic review and meta-analysis. PLoS Negl Trop Dis. 2015;9(2):e0003525. doi: 10.1371/journal.pntd.0003525. 
21. Pestehchian N, Etemadifarr M, Yousefi HA, Chiani M, Aslani N, Nasr Z. Frequency of blood-tissue parasitic infections in patients with multiple sclerosis, as compared to their family members. Int J Prev Med. 2014;5(12):1578-1581.

22. Bilgrami M, O’Keefe P. Neurologic diseases in HIV-infected patients. Handb Clin Neurol. 2014;121:1321-1344.

23. Heitman BB, Irizarry AF. Recognition and management of toxoplasmosis. Nurse Pract. 1997;22(9):75, 79-82, 85-86.

24. Prandota J. The importance of Toxoplasma gondii infection in diseases presenting with headaches. Headaches and aseptic meningitis may be manifestations of the Jarisch-Herxheimer reaction. Int J Neurosci. 2009;119(12):2144-2182.

25. Delgado García G, García Landa J. Reactivity of the intradermal test with toxoplasmosis in schizophrenic patients. Rev Cubana Med Trop. 1979;31(3):225-231.

26. Choi WY, Yoo JE, Chung CS, Paik KK, Cho SN. Toxoplasma antibodies by indirect latex agglutination tests in national Seoul mental hospital patients. Kisaengchunghak Chapchi. 1983;21(2):281-285.

27. Yolken RH, Bachmann S, Ruslanova I, et al. Antibodies to Toxoplasma gondii in individuals with first-episode schizophrenia. Clin Infect Dis. 2001;32(5):842-844.

28. Park MH, Kwon YJ, Jeong HY, et al. Association between intracellular infectious agents and schizophrenia. Clin Psychopharmacol Neurosci. 2012;10(2):117-123.

29. James BO, Agbonile IO, Okolo M, Lawani AO, Omoaregba JO. Prevalence of Toxoplasma gondii infection among individuals with severe mental illness in Nigeria: a case control study. Pathog Glob Health. 2013;107(4):189-193.

30. Emelia O, Amal RN, Ruzanna ZZ, et al. Seroprevalence of antiToxoplasma gondii IgG antibody in patients with schizophrenia. Trop Biomed. 2012;29(1):151-159.

31. Cetinkaya Z, Yazar S, Gecici O, Namli MN. Anti-Toxoplasma gondii antibodies in patients with schizophrenia - preliminary findings in a Turkish sample. Schizophr Bull. 2007;33(3):789-791.

32. Hamidinejat H, Ghorbanpoor M, Hosseini H, et al. Toxoplasma gondii infection in first-episode and inpatient individuals with schizophrenia. Int J Infect Dis. 2010;14(11):e978-e981.

33. Alvarado-Esquivel C, Urbina-Álvarez JD, Estrada-Martínez S, et al. Toxoplasma gondii infection and schizophrenia: a case control study in a low Toxoplasma seroprevalence Mexican population. Parasitol Int. 2011;60(2):151-155.

34. Zhu S, Guo MF, Feng QC, Fan JM, Zhang LX. Epidemiological evidences from China assume that psychiatric-related diseases may be associated with Toxoplasma gondii infection. Neuro Endocrinol Lett. 2007;28(2):115-120.

35. Arias I, Sorlozano A, Villegas E, et al. Infectious agents associated with schizophrenia: a meta-analysis. Schizophr Res. 2012;136(1-3): 128-136.

36. Dupont CD, Christian DA, Hunter CA. Immune response and immunopathology during toxoplasmosis. Semin Immunopathol. 2012;34(6): 793-813.

37. Maksimov P, Zerweck J, Maksimov A, et al. Peptide microarray analysis of in silico-predicted epitopes for serological diagnosis of Toxoplasma gondii infection in humans. Clin Vac Immunol. 2012;19:865-874

38. Flegr J. Schizophrenia and Toxoplasma gondii: an underevaluated association. Expert Rev Anti Infect Ther. 2015;31:1-4.

39. Pearce BD, Kruszon-Moran D, Jones JL. The relationship between Toxoplasma gondii infection and mood disorders in the third National Health and Nutrition Survey. The relationship between Toxoplasma gondii infection and mood disorders in the third National Health and Nutrition Survey. Biol Psychiat. 2012;72(4):290-295.

40. Hamdani N, Daban-Huard C, Lajnef M, et al. Relationship between Toxoplasma gondii infection and bipolar disorder in a French sample. $J$ Affect Disord. 2013;148(2-3):444-448.

41. Dickerson F, Stallings C, Origoni A, et al. Antibodies to Toxoplasma gondii in individuals with mania. Bipolar Disord. 2014;16(2):129-136.
42. Gale SD, Brown BL, Berrett A, Erickson LD, Hedges DW. Association between latent toxoplasmosis and major depression, generalised anxiety disorder and panic disorder in human adults. Folia Parasitol (Praha). 2014;61(4):285-292.

43. Hinze-Selch, D, Däubener W, Erdag E, Wilms S. The diagnosis of a personality disorder increases the likelihood for seropositivity to Toxoplasma gondii in psychiatric patients. Folia Parasitol (Praha). 2010;57:129-135.

44. Jones-Brando L, Torrey EF, Yolken R. Drugs used in the treatment of schizophrenia and bipolar disorder inhibit the replication of Toxoplasma gondii. Schizophr Res. 2003;62(3):237-244.

45. Fond G, Macgregor A, Tamouza R, et al. Comparative analysis of anti-toxoplasmic activity of antipsychotic drugs and valproate. Eur Arch Psychiatry Clin Neurosci. 2014;264(2):179-183.

46. Wang HL, Xiang YT, Li QY, et al. The effect of artemether on psychotic symptoms and cognitive impairment in first-episode, antipsychotic drug-naive persons with schizophrenia seropositive to Toxoplasma gondii. J Psychiatr Res. 2014;53:119-124.

47. Dickerson FB, Stallings CR, Boronow JJ, Origoni AE, Yolken RH. A double-blind trial of adjunctive azithromycin in individuals with schizophrenia who are seropositive for Toxoplasma gondii. Schizophr Res. 2009;112(1-3):198-199.

48. Stock AK, Heintschel von Heinegg E, Köhling HL, Beste C. Latent Toxoplasma gondii infection leads to improved action control. Brain Behav Immun. 2014;37:103-108.

49. Pearce BD, Hubbard S, Rivera HN, et al. Toxoplasma gondii exposure affects neural processing speed as measured by acoustic startle latency in schizophrenia and controls. Schizophr Res. 2013; 150(1):258-261.

50. Priplatova L, Sebankova B, Flegr J. Contrasting effect of prepulse signals on performance of toxoplasma-infected and toxoplasma-free subjects in an acoustic reaction times test. PLoS One. 2014;9(11):e112771.

51. Zhang Y, Träskman-Bendz L, Janelidze S, et al. Toxoplasma gondii immunoglobulin $\mathrm{G}$ antibodies and nonfatal suicidal self-directed violence. J Clin Psychiatry. 2012;73(8):1069-1076.

52. Pedersen MG, Mortensen PB, Norgaard-Pedersen B, Postolache TT. Toxoplasma gondii infection and self-directed violence in mothers. Arch Gen Psychiatry. 2012;69(11):1123-1130.

53. Alvarado-Esquivel C, Sánchez-Anguiano LF, Arnaud-Gil CA, et al. Toxoplasma gondii infection and suicide attempts: a case-control study in psychiatric outpatients. J Nerv Ment Dis. 2013;201(11):948-952.

54. Alvarado-Esquivel C, Alvarado-Esquivel D, Dubey JP. Prevalence of Toxoplasma gondii antibodies in domestic donkeys (Equus asinus) in Durango, Mexico slaughtered for human consumption. BMC Vet Res. 2015;11(1):6.

55. Alvarado-Esquivel C, Pacheco-Vega SJ, Hernández-Tinoco J, et al. Lack of association between Toxoplasma gondii infection and occupational exposure to animals. Eur J Microbiol Immunol (Bp). 2014; 4(4):184-192.

56. Alvarado-Esquivel $\mathrm{C}$, Pacheco-Vega $\mathrm{S}$, Hernández-Tinoco J, et al. Toxoplasma gondii infection in interstate truck drivers: a case-control seroprevalence study. Parasit Vectors. 2015;8(1):77.

57. Jones JL, Parise ME, Fiore AE. Neglected parasitic infections in the United States: toxoplasmosis. Am J Trop Med Hyg. 2014;90(5):794-799.

58. Ayral F, Artois J, Zilber AL, et al. The relationship between socioeconomic indices and potentially zoonotic pathogens carried by wild Norway rats: a survey in Rhône, France (2010-2012). Epidemiol Infect. 2015;143(3):586-599.

59. Xu P, Li X, Guo L, et al. Seroprevalence of Toxoplasma gondii infection in Liaoning cashmere goat from northeastern China. Parasite. $2014 ; 21: 22$

60. Flegr J. How and why Toxoplasma makes us crazy. Trends Parasitol. 2013;29(4):156-163.

61. Flegr J. Influence of latent Toxoplasma infection on human personality, physiology and morphology: pros and cons of the Toxoplasmahuman model in studying the manipulation hypothesis. J Exp Biol. 2013;216(Pt 1):127-133 
62. Dickerson F, Stallings C, Origoni A, et al. Antibodies to Toxoplasma gondii and cognitive functioning in schizophrenia, bipolar disorder, and nonpsychiatric controls. J Nerv Ment Dis. 2014;202(8):589-593.

63. Pearce BD, Kruszon-Moran D, Jones JL. The association of Toxoplasma gondii infection with neurocognitive deficits in a populationbased analysis. Soc Psychiatry Psychiatr Epidemiol. 2014;49(6): 1001-1010.

64. Gajewski PD, Falkenstein M, Hengstler JG, Golka K. Toxoplasma gondii impairs memory in infected seniors. Brain Behav Immun. 2014;36: 193-199.

65. Beste C, Getzmann S, Gajewski PD, Golka K, Falkenstein M. Latent Toxoplasma gondii infection leads to deficits in goal-directed behavior in healthy elderly. Neurobiol Aging. 2014;35(5):1037-1044.

66. Gale SD, Brown BL, Erickson LD, Berrett A, Hedges DW. Association between latent toxoplasmosis and cognition in adults: a cross-sectional study. Parasitology. 2015;142(4):557-565.

67. Carter CJ. Toxoplasmosis and polygenic disease susceptibility genes: extensive Toxoplasma gondii host/pathogen interactome enrichment in nine psychiatric or neurological disorders. J Pathog. 2013; 2013:965046.

68. Notarangelo FM, Wilson EH, Horning KJ, et al. Evaluation of kynurenine pathway metabolism in Toxoplasma gondii-infected mice: implications for schizophrenia. Schizophr Res. 2014;152(1):261-267.

69. Henriquez SA, Brett R, Alexander J, Pratt J, Roberts CW. Neuropsychiatric disease and Toxoplasma gondii infection. Neuroimmunomodulation. 2009;16(2):122-133.

70. Xiao J, Li Y, Prandovszky E, et al. MicroRNA-132 dysregulation in Toxoplasma gondii infection has implications for dopamine signaling pathway. Neuroscience. 2014;268:128-138.

71. Jia B, Lu H, Liu Q, Yin J, Jiang N, Chen Q. Genome-wide comparative analysis revealed significant transcriptome changes in mice after Toxoplasma gondii infection. Parasit Vectors. 2013;6:161.

72. Bhadra R, Cobb DA, Weiss LM, Khan IA. Psychiatric disorders in toxoplasma seropositive patients - the CD8 connection. Schizophr Bull. 2013;39(3):485-489.

73. Yarovinsky F. Innate immunity to Toxoplasma gondii infection. Nat Rev Immunol. 2014;14(2):109-121.

74. Suzuki Y, Sa Q, Gehman M, Ochiai E. Interferon-gamma- and perforinmediated immune responses for resistance against Toxoplasma gondii in the brain. Expert Rev Mol Med. 2011;13:e31.

75. Severance EG, Kannan G, Gressitt KL, et al. Anti-gluten immune response following Toxoplasma gondii infection in mice. PLoS One. 2012; 7(11):e50991.

76. Cohen SB, Denkers EY. The gut mucosal immune response to Toxoplasma gondii. Parasite Immunol. 2015;37(3):108-117.
77. Severance EG, Yolken RH, Eaton WW. Autoimmune diseases, gastrointestinal disorders and the microbiome in schizophrenia: more than a gut feeling. Schizophr Res. 2014. pii: S0920-964(14)00319-3.

78. Severance EG, Alaedini A, Yang S, et al. Gastrointestinal inflammation and associated immune activation in schizophrenia. Schizophr Res. 2012;138(1):48-53.

79. Severance EG, Gressitt KL, Yang S, et al. Seroreactive marker for inflammatory bowel disease and associations with antibodies to dietary proteins in bipolar disorder. Bipolar Disord. 2014;16(3):230-240.

80. Reeves GM, Mazaheri S, Snitker S, et al. A positive association between T. gondii seropositivity and obesity. Front Public Health. 2013;1:73.

81. Flegr J, Príplatova L, Hampl R, Bicikovía M, Ripova D, Mohr P. Difference of neuro- and immunomodulatory steroids and selected hormone and lipid concentrations between Toxoplasma-free and Toxoplasma-infected but not CMV-free and CMV-infected schizophrenia patients. Neuro Endocrinol Lett. 2014;35(1):20-27.

82. Portugal LR, Fernandes LR, Alvarez-Leite JI. Host cholesterol and inflammation as common key regulators of toxoplasmosis and artherosclerosis development. Expert Rev Anti Infect Ther. 2009; 7(7):807-819.

83. Harker KS, Ueno N, Wang T, Bonhomme C, Liu W, Lodoen MB. Toxoplasma gondii modulates the dynamics of human monocyte adhesion to vascular endothelium under fluidic shear stress. J Leukoc Biol. 2013;93(5):789-800.

84. Sirota P, Hadi E, Djaldetti M, Bessler H. Difference in inflammatory cytokine production by mononuclear cells from obese and non-obese schizophrenic patients. Acta Psychiatr Scand. 2015. doi: 10.1111/ acps.12396.

85. Knolle-Veentjer S, Huth V, Ferstl R, Aldenhoff JB, Hinze-Selch D. Delay of gratification and executive performance in individuals with schizophrenia: putative role for eating behavior and body weight regulation. J Psychiatr Res. 2008;42(2):98-105.

86. Sutterland AL, Fond G, Kuin A, et al. Beyond the association. Toxoplasma gondii in schizophrenia, bipolar disorder, and addiction: systematic review and meta-analysis. Acta Psychiatr Scand. 2015;15. doi: $10.1111 /$ acps. 12423 .

87. Koch JM, Hinze-Selch D, Stingele K, et al. Changes in CREB phosphorylation and BDNF plasma levels during psychotherapy of depression. Psychother Psychosom. 2009;78(3):187-192.

88. Müller KU, Mennigen E, Ripke S, et al. Altered reward processing in adolescents with prenatal exposure to maternal cigarette smoking. JAMA Psychiatry. 2013;70(8):847-856.

89. Potthast N, Neuner F, Catani C. The contribution of emotional maltreatment to alcohol dependence in a treatment-seeking sample. Addict Behav. 2014;39(5):949-958.
Reports in Parasitology

\section{Publish your work in this journal}

Reports in Parasitology is international, peer-reviewed, open access journal publishing original research, reports, reviews and commentaries on all areas of parasitology. The manuscript management system is completely online and includes a very quick and fair peer-review

\section{Dovepress}

system. Visit http://www.dovepress.com/testimonials.php to read real quotes from published authors. 